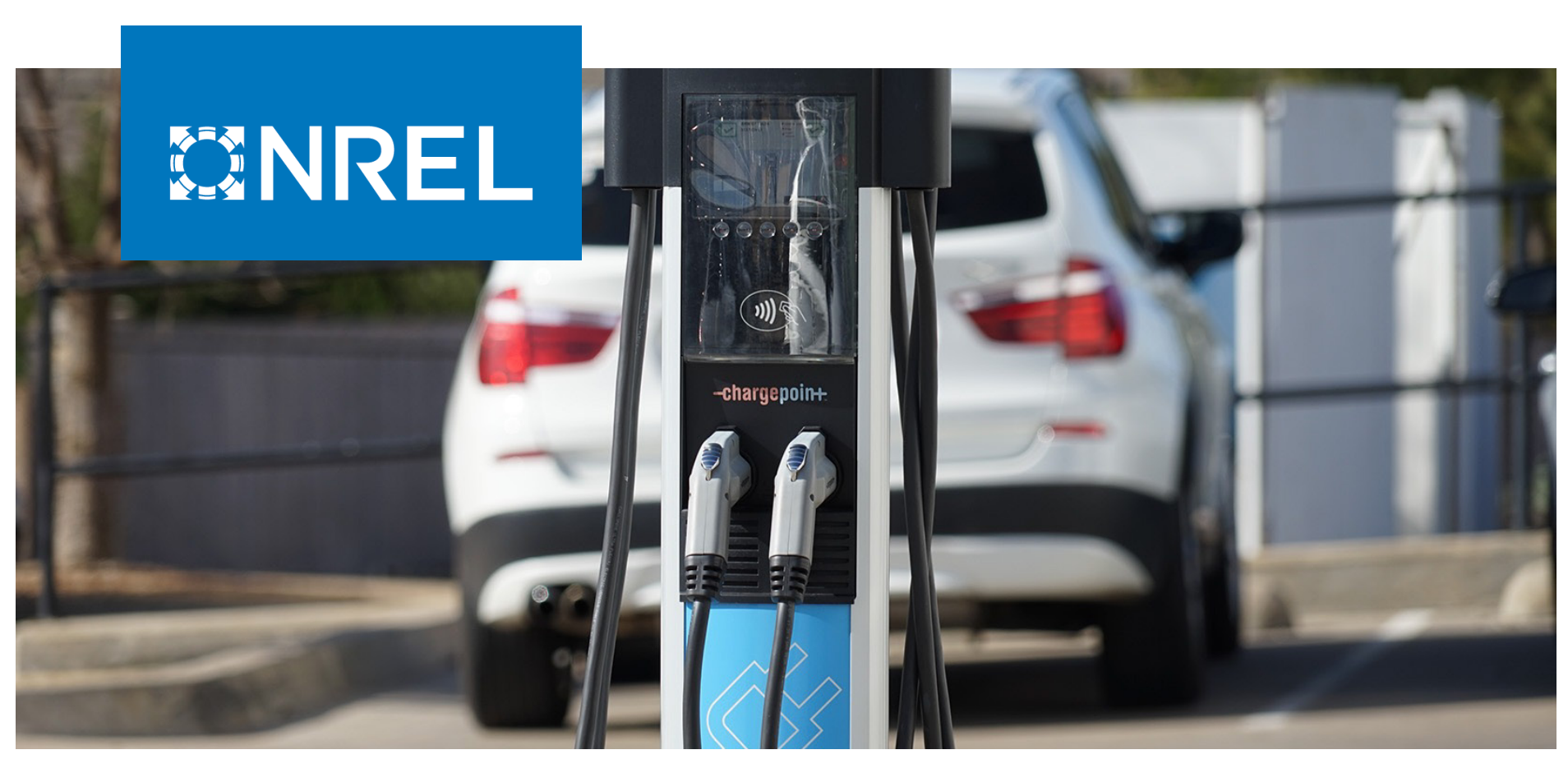

\title{
Electric Vehicle Charging Infrastructure Trends from the Alternative Fueling Station Locator: Third Quarter 2020
}

Abby Brown, ${ }^{1}$ Stephen Lommele, ${ }^{1}$ Alexis Schayowitz, ${ }^{2}$ and Emily Klotz ${ }^{2}$

1 National Renewable Energy Laboratory 2 ICF

NREL is a national laboratory of the U.S. Department of Energy Office of Energy Efficiency \& Renewable Energy

Operated by the Alliance for Sustainable Energy, LLC

This report is available at no cost from the National Renewable Energy Laboratory (NREL) at www.nrel.gov/publications.
Technical Report

NREL/TP-5400-79536

May 2021 


\title{
GNREL
}

\section{Electric Vehicle Charging Infrastructure Trends from the Alternative Fueling Station Locator: Third Quarter 2020}

\author{
Abby Brown, ${ }^{1}$ Stephen Lommele, ${ }^{1}$ Alexis Schayowitz, ${ }^{2}$ \\ and Emily Klotz ${ }^{2}$
}

1 National Renewable Energy Laboratory

2 ICF

\section{Suggested Citation}

Brown, Abby, Stephen Lommele, Alexis Schayowitz, and Emily Klotz. 2021. Electric

Vehicle Charging Infrastructure Trends from the Alternative Fueling Station Locator: Third

Quarter 2020. Golden, CO: National Renewable Energy Laboratory.

NREL/TP-5400-79536. https://www.nrel.gov/docs/fy21osti/79536.pdf.

NREL is a national laboratory of the U.S. Department of Energy Office of Energy Efficiency \& Renewable Energy Operated by the Alliance for Sustainable Energy, LLC

This report is available at no cost from the National Renewable Energy Laboratory (NREL) at www.nrel.gov/publications.

Contract No. DE-AC36-08GO28308
Technical Report

NREL/TP-5400-79536

May 2021

National Renewable Energy Laboratory 15013 Denver West Parkway Golden, CO 80401

303-275-3000 • www.nrel.gov 


\section{NOTICE}

This work was authored in part by the National Renewable Energy Laboratory, operated by Alliance for Sustainable Energy, LLC, for the U.S. Department of Energy (DOE) under Contract No. DE-AC3608GO28308. Funding provided by U.S. Department of Energy Office of Energy Efficiency and Renewable Energy's Vehicle Technologies Office. The views expressed herein do not necessarily represent the views of the DOE or the U.S. Government.

This report is available at no cost from the National

Renewable Energy Laboratory (NREL) at

www.nrel.gov/publications.

U.S. Department of Energy (DOE) reports produced

after 1991 and a growing number of pre-1991

documents are available

free via www.OSTI.gov.

Cover Photo by Tulsa Clean Cities: NREL 51475.

NREL prints on paper that contains recycled content. 


\section{Acknowledgments}

Funding for this report came from the U.S. Department of Energy Office of Energy Efficiency and Renewable Energy's Vehicle Technologies Office. The Station Locator team collected the data used to generate this report with the help of electric vehicle (EV) charging networks, charging infrastructure providers and developers, Clean Cities Coalition Network coordinators, industry associations, original equipment manufacturers, state and local government agencies, utilities, fleets, EV drivers, and other industry stakeholders. The authors relied on the valuable contributions of reviewers, including Eric Wood, National Renewable Energy Laboratory; Kevin Wood, Center for Sustainable Energy/San Diego Clean Cities; Joseph Cryer, Southern California Association of Governments/Southern California Clean Cities, and Dan Bowerson, Alliance for Automotive Innovation. 


\section{List of Acronyms}

AFDC

API

BN

CCS

CPN

DC

DOE

E85

EA

EV

EVC

EVGATEWAY

EVN

EVSE

EVSP

FCN

FLO

FPLEV

GRN

$\mathrm{kW}$

L1

L2

MUD

NON

NREL

OC

OCPI

OEM

PEV

PHEV

POWERFLEX

Q1

Q2

Q3

SCN

TESLA

TESLAD

VLTA

WEB
Alternative Fuels Data Center

application program interface

Blink network

Combined Charging System

ChargePoint network

direct-current

U.S. Department of Energy

ethanol blend containing $51 \%$ to $83 \%$ ethanol, depending on geography

and season

Electrify America network

all-electric vehicle

EV Connect network

evGateway network

EVgo network

electric vehicle supply equipment

electric vehicle service provider

Francis network

FLO network

FPL EVolution

Greenlots network

kilowatt

Level 1 charger

Level 2 charger

multi-unit dwelling, also referred to as multi-family building

non-networked

National Renewable Energy Laboratory

OpConnect network

Open Charge Point Interface

original equipment manufacturer

plug-in electric vehicle

plug-in hybrid electric vehicle

Powerflex network

quarter 1, or first quarter of the calendar year

quarter 2 , or second quarter of the calendar year

quarter 3 , or third quarter of the calendar year

SemaConnect network

Tesla Supercharger network

Tesla Destination network

Volta network

Webasto network 


\section{Executive Summary}

The US. Department of Energy's (DOE's) Alternative Fueling Station Locator contains information on public and private non-residential alternative fueling stations in the United States and Canada and currently tracks ethanol (E85), biodiesel, compressed natural gas, electric vehicle (EV) charging, hydrogen, liquefied natural gas, and propane stations. Of these fuels, EV charging continues to experience rapidly changing technology and growing infrastructure. This report provides a snapshot of the state of EV charging infrastructure in the United States in the third calendar quarter of 2020 (Q3). Using data from the Station Locator, this report breaks down the growth of public and private charging infrastructure by charging level, network, and location. Additionally, this report measures the current state of charging infrastructure compared with the amount projected to meet charging demand by 2030. This information is intended to help transportation planners, policymakers, researchers, infrastructure developers, and others understand the rapidly changing landscape for EV charging. This is the third report in a series. Previous reports for the first (Q1) and second (Q2) calendar quarters of 2020 can be found in the Alternative Fuels Data Center's (AFDC) and National Renewable Energy Laboratory (NREL) publication databases.

In Q3, all categories of electric vehicle supply equipment (EVSE) grew, except for public and private Level 1 EVSE, which decreased by $2.1 \%$ and $0.7 \%$, respectively. Overall, there was a $6.6 \%$ increase in the number of EVSE in the Station Locator. The majority of EVSE in the Station Locator are Level 2, though direct-current (DC) fast charger EVSE grew by the largest percentage in Q3. The Mid-Atlantic region had the largest increase in public charging infrastructure in Q3, though California continues to lead the country in the number of available public EVSE.

NREL's 2017 “National Plug-In Electric Vehicle Infrastructure Analysis” estimated how much public and workplace charging infrastructure would be required in the United States to meet charging demand for a central scenario in which 15 million light-duty plug-in electric vehicles (PEVs) are on the road by 2030 (601,000 Level 2 and 27,500 DC fast EVSE) (Wood 2017). Based on this analysis, about $57.3 \%$ and $13.2 \%$ of the necessary DC fast and Level 2 EVSE, respectively, have been installed as of Q3. However, in Q3, the number of DC fast EVSE and Level 2 EVSE per 1,000 PEVs was 10.2 and 51.5 respectively, compared with NREL's projected need of 1.8 and 40.1, respectively. This indicates that infrastructure development is keeping up with, and even surpassing, charging demand. It is important to note that the majority (55.1\%) of public DC fast EVSE in the Station Locator are on the Tesla network and are therefore only readily accessible to Tesla drivers. 


\section{Table of Contents}

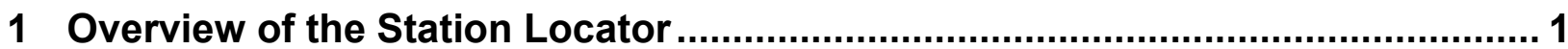

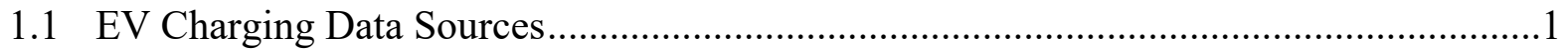

1.1.1 Data from Charging Network APIs .................................................................

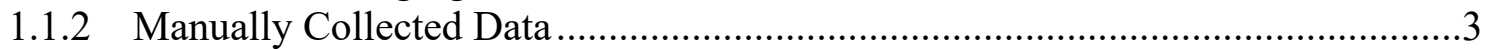

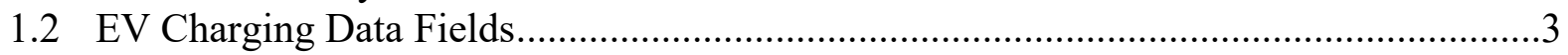

2 Electric Vehicle Charging Infrastructure Trends................................................. 5

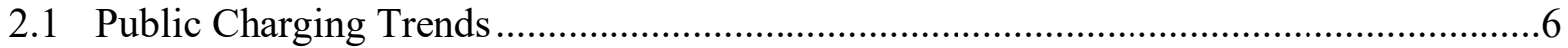

2.1.1 By Charging Level ................................................................................6

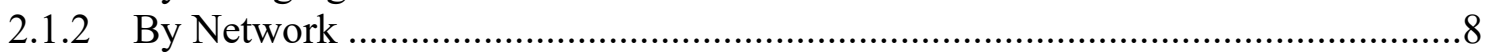

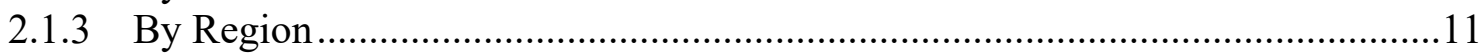

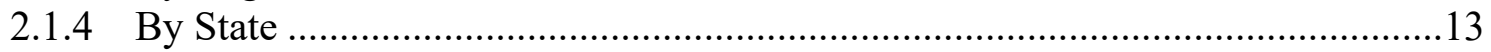

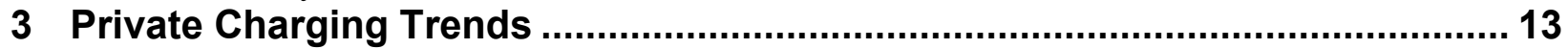

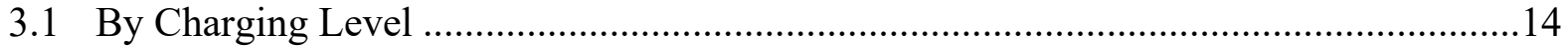

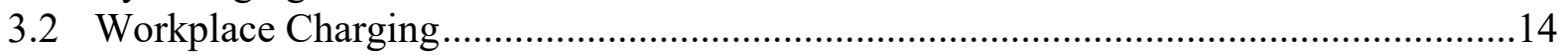

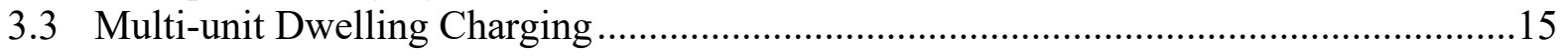

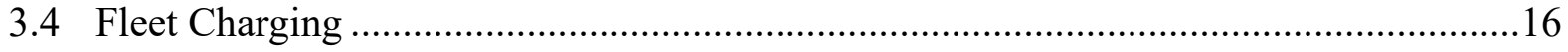

4 Projecting Future Charging Infrastructure Needs............................................... 16

5 Developments That Could Impact Future Quarters ......................................... 18

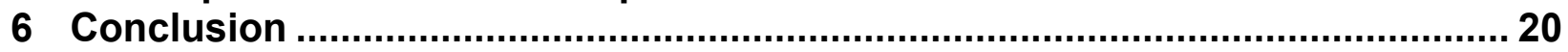

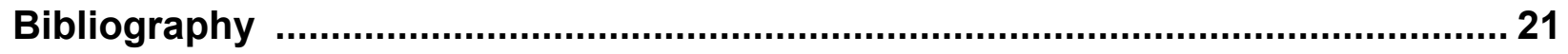




\section{List of Figures}

Figure 1. Non-Networked vs. Networked EV Charging Stations................................................2

Figure 2. Timeline of API Integrations in the Station Locator. ..................................................2

Figure 3. EV Charging Infrastructure Hierarchy as Defined in OCPI (EVRoaming Foundation, n.d.).

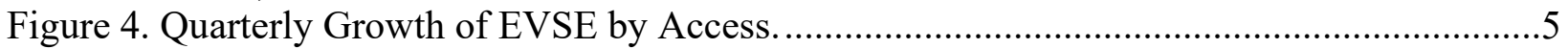

Figure 5. Quarterly Growth of Public EVSE by Charging Level..............................................6

Figure 6. Quarterly Growth of Public DC Fast EVSE by Power Output. ....................................7

Figure 7. Quarterly Growth of Public DC Fast Connectors by Type. .......................................8

Figure 8. Breakdown of Public EVSE by Network and Charging Level in Q3. ........................10

Figure 9. Quarterly Growth of Public EVSE by Network. ...................................................... 11

Figure 10. Clean Cities Regions. ........................................................................................... 12

Figure 11. Quarterly Growth of Public EVSE by Clean Cities Region.....................................12

Figure 12. Quarterly Growth of Private EVSE by Charging Level.........................................14

Figure 13. Quarterly Growth of Private Workplace EVSE by Charging Level. ...........................15

Figure 14. Quarterly Growth of Private MUD EVSE by Charging Level.................................16

Figure 15. Current Availability and Projected 2030 Need of Public and Workplace Charging in the United States.

Figure 16. Current Availability and Projected 2030 Need of Public and Workplace EVSE per 1,000 EVs in the United States.

\section{List of Tables}

Table 1. Quarterly Growth of Public EVSE by Network. 11

Table 2. States with the Highest Rate of EVSE per 100,000 People......

Table 3. States with the Largest Growth of EVSE per 100,000 People. 


\section{Overview of the Station Locator}

The U.S. Department of Energy's (DOE) Alternative Fuels Data Center (AFDC) launched in 1991 in response to the Alternative Motor Fuels Act of 1988 and the Clean Air Act Amendments of 1990 (Alternative Fuels Data Center, n.d.a.). Originally, it served as a hard copy resource for alternative fuel performance data and eventually became an internet resource in 1995 . Since then, the AFDC has evolved dramatically into a robust online resource that provides a broad range of information on alternative fuels and advanced transportation technologies, including fueling and charging station data. In 2017, NREL partnered with National Resources Canada to expand the dataset to include the location of those same alternative fuel stations across Canada as the Electric Charging and Alternative Fueling Stations Locator, or Localisateur de stations de recharge et de stations de ravitaillement en carburants de remplacement (Levene et al., 2019). The Station Locator database now includes information on public and private non-residential alternative fueling stations in the United States and Canada and currently tracks ethanol (E85), biodiesel, compressed natural gas, electric vehicle (EV) charging, hydrogen, liquefied natural gas, and propane stations.

While historical data for all fuel types in the Station Locator are available, it is especially important to take an in-depth look at EV charging due to rapidly changing technology and growing infrastructure. As original equipment manufacturers (OEMs) offer more EV models, more utilities begin offering incentives for EVs and infrastructure, and states and municipalities set electrification goals, this trend is likely to continue. Using Station Locator data, this paper explores the growth of both public and private EV charging infrastructure in the United States for the third calendar quarter of 2020 (Q3). This is the third report in a series. Previous reports for the first (Q1) and second (Q2) calendar quarters of 2020 can be found in the Alternative Fuels Data Center's (AFDC) and National Renewable Energy Laboratory (NREL) publication databases.

\subsection{EV Charging Data Sources}

NREL and its data collection contractor and collaborator, ICF, use a variety of methods to gather and verify EV charging data in the Station Locator. Electric vehicle service providers (EVSPs), responsible for managing a network of EV charging stations (Fig. 1), share data directly with the Station Locator team and are the largest data source for EV charging in the Station Locator. In 
addition, data are collected through industry outreach, Clean Cities coordinators, and other manual methods.

\section{Non-Networked Stations}

Non-networked EV charging stations are not connected to the internet and provide basic charging functionality without advanced communications capabilities. Because of this, non-networked charging is generally free or offered as an amenity for those who pay for parking or to access a business.

\section{Networked Stations}

Networked EV charging stations are connected to the internet via a cable or wireless technology and can communicate with the backend computer system of an EVSP. Being connected to a network lets station owners or site hosts manage who can access stations and control how much it costs drivers to charge their vehicle. An EVSP typically manages a group of networked EVSE and may use its communication capabilities to communicate directly with drivers, other EVSPs, or utilities; monitor and share real-time station status; broadcast location information; collect and store usage data; control access; or facilitate payment.

Figure 1. Non-Networked vs. Networked EV Charging Stations.

\subsubsection{Data from Charging Network APIs}

Prior to 2014, NREL manually collected all EV charging data, including EV charging stations managed by EVSPs. In 2014, to keep up with the rapid growth of charging infrastructure, NREL began incorporating daily updates on networked charging station data directly from EVSPs when available. NREL does this by accessing the network's application program interface (API) and importing each network's API data into the database. Using APIs ensures the efficiency, accuracy, and completeness of the data is maintained.

Fig. 2 shows a timeline of the integration of the network APIs into the Station Locator data management process. Open Charge Point Interface (OCPI)-based APIs that have been integrated into the Station Locator are also shown in Fig. 2. See section 1.2 for more information on OCPI.

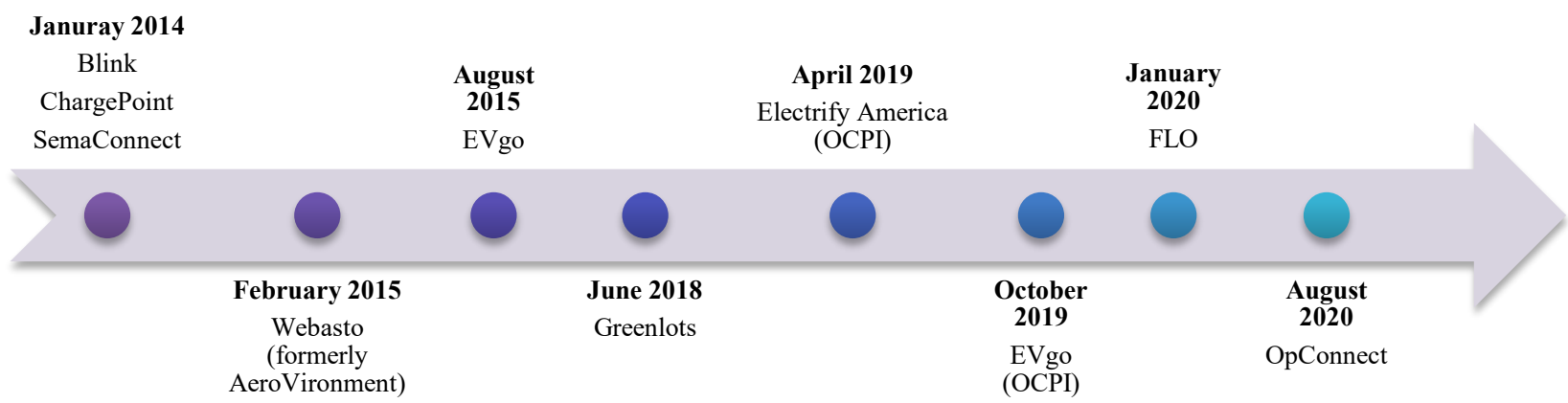

Figure 2. Timeline of API Integrations in the Station Locator.

As of September 2020, there were 30,323 public and private charging stations in the database, which are available on the Station Locator or accessible via API or data download (Alternative Fuels Data Center, n.d.b.). Of those, approximately 55\% are automatically updated daily via EVSP-provided APIs while the rest are managed and updated manually. 
The Station Locator team is working with additional EVSPs to access and integrate existing APIs or provide them with best practices on developing an API if they have not yet automated their data sharing. This will help ensure that station data is as current and accurate as possible, while also increasing the efficiency of the EV charging data update process.

\subsubsection{Manually Collected Data}

For non-networked (i.e., not connected to the internet) stations, data sources include trade media, Clean Cities coordinators, a Submit New Station form on the Station Locator website, EV charging station manufacturers, electric utilities, OEMs, state and municipal governments, private companies, and others. The Station Locator team regularly monitors news outlets for press releases on new EV charging station openings and seeks out more information as appropriate to confirm and add the EV charging data to the Station Locator.

The Station Locator team also receives semi-regular data in the form of spreadsheets from EVSPs that do not have an API available. These EVSPs include EV Connect, Tesla, and Volta. In Q3, the team received an update from the EV Connect and Tesla Supercharger networks. Additionally, the team receives regular updates from Chargeway that includes stations on all networks. The team is greatly appreciative of their continued collaboration and willingness to share regular data updates.

Finally, Clean Cities coalitions (see section 2.1.3) proactively provide information on station updates and additions throughout the year. Coalitions also serve as a valuable on-the-ground resource for stations that ICF is not able to confirm through normal station confirmation processes. Unconfirmed stations are sent to coalitions throughout the year for confirmation; if the coalition is not able to provide any additional information, the station is subsequently removed from the Station Locator.

It is important to state that these reports reflect a snapshot of the number of EVSE in the Station Locator at the end of each quarter. Therefore, notable changes may be attributed to the manual data collection process as new manually added EVSE is counted in the quarter in which it is added to the Station Locator as opposed to when the infrastructure was installed.

\subsection{EV Charging Data Fields}

Current charging infrastructure in the Station Locator generally falls into the following categories:

- Public: A broad category that includes EV charging located in publicly accessible areas or along highway corridors.

- Workplace: EV charging intended to provide charging to employees during the workday.

- Commercial/Fleet: EV charging intended to provide charging for electric fleet vehicles, including municipal/private fleets, car sharing, and transportation network companies.

Note that while fleet data exists in the Station Locator, stations solely for fleet use are not yet designated as such in the Station Locator. The Station Locator team has recently added this level of tracking and will therefore be able to designate stations as such moving forward. See section 3.4 for more details. 
Additionally, the Station Locator does not maintain data on single-family residential charging and has minimal, yet expanding, data on charging at multi-unit dwellings (MUDs, also referred to as multi-family buildings). See section 3.3 for additional details.

In 2019, the Station Locator team began transitioning its counting logic to align with the hierarchy defined in the OCPI protocol: locations, electric vehicle supply equipment (EVSE), and connectors (EVRoaming Foundation, n.d.), as shown in Fig. 3 and described below. With this transition, the Station Locator is now counting the number of EVSE at a station location, rather than the number of connectors previously counted.

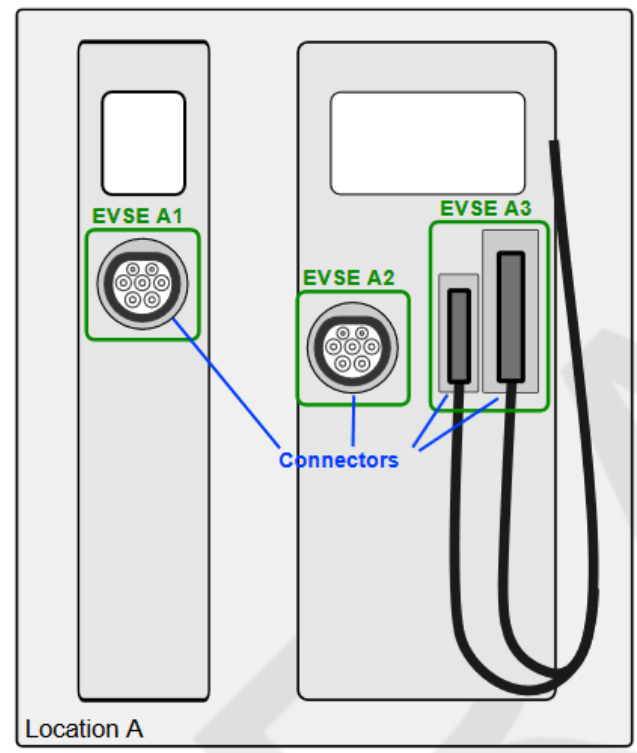

Figure 3. EV Charging Infrastructure Hierarchy as Defined in OCPI (EVRoaming Foundation, n.d.).

The following fuel-specific fields are tracked in the Station Locator for EV charging stations (Alternative Fuels Data Center, n.d.c.):

- EV charger information:

- EV charging station: one or more EVSE located at the same address

- EVSE count: the number of outlets or ports (i.e., the number of vehicles that can simultaneously charge at a charging station)

- Charger type

- Level 1 (L1): 120V; 1 hour of charging $=2-5$ miles of range

- Level 2 (L2): 240V; 1 hour of charging $=10-20$ miles of range

- Direct-current (DC) fast: $480 \mathrm{~V}+; 20$ minutes of charging $=60-80$ miles of range

- Connectors (number and type)

- NEMA: for Level 1 chargers

- J1772: for Level 1 and Level 2 chargers

- Combined Charging System (CCS): for DC fast chargers 
- CHAdeMO: for DC fast chargers

- Tesla: for all charging levels for Tesla vehicles
○ Network
- Manufacturer
○ Power output (kilowatts, kW)

- Open date

- Workplace

- Pricing

- On-site renewable electricity source.

These fields and the associated definitions are used in the analysis that follows.

\section{Electric Vehicle Charging Infrastructure Trends}

The purpose of this paper is to identify EV charging infrastructure trends for Q3 of 2020. However, as previously mentioned, the Station Locator has been collecting data on alternative fueling stations since the 1990s and therefore has historical EV charging station data for several years that can serve as a baseline for more analysis. See the first report in this series for the growth of EVSE and EV charging stations in the Station Locator over the last ten years.

In Q3, the number of EVSE in the Station Locator grew by $6.6 \%$, or 6,360 EVSE. Public EVSE grew by $7.0 \%$, and account for the majority of EVSE in the Station Locator (Fig. 4). Private EVSE grew by $4.3 \%$ (Fig. 4).

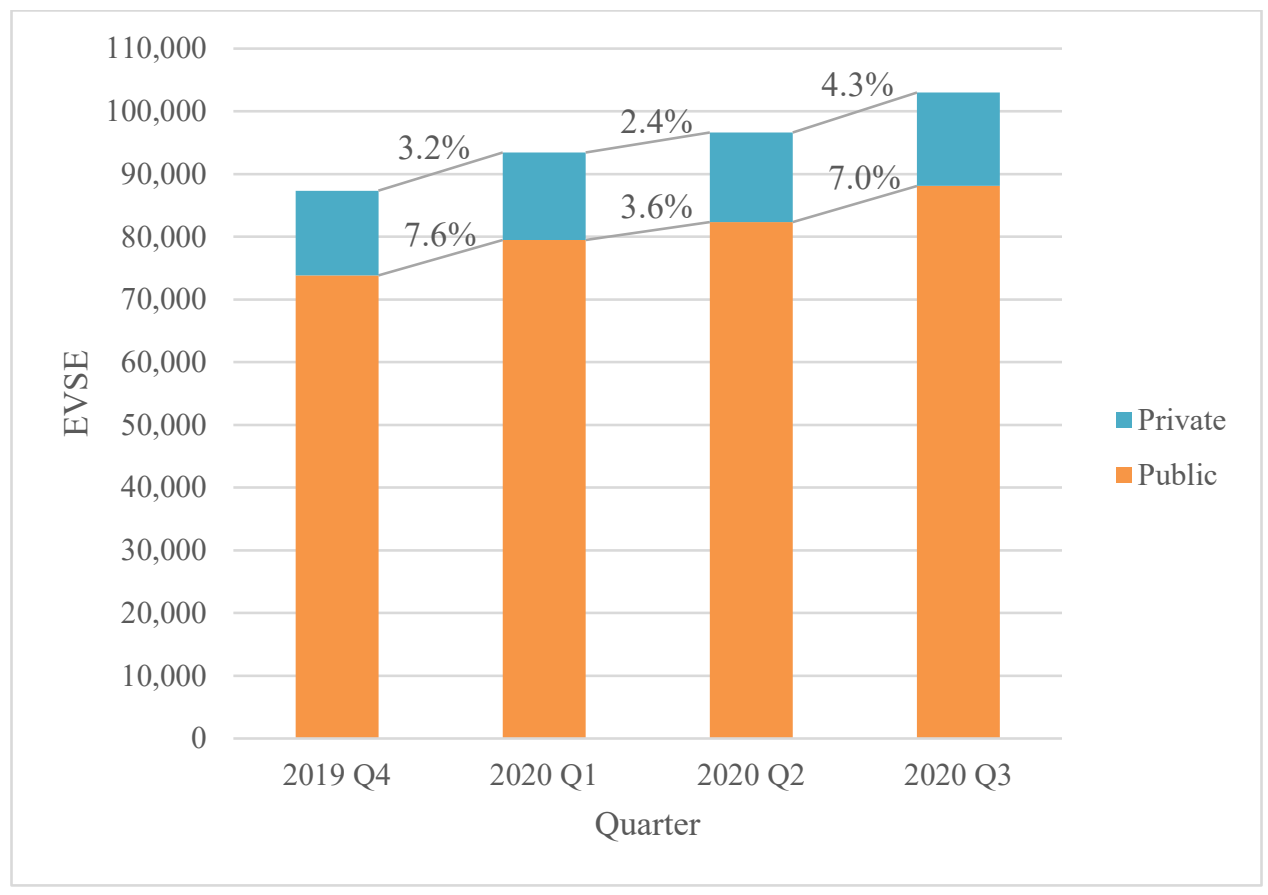

Figure 4. Quarterly Growth of EVSE by Access. 
The following sections break down the growth of public and private EVSE further to highlight what types of EV infrastructure grew in Q3 and where EV infrastructure has grown geographically. Since the number of EVSE represents the number of vehicles that can charge simultaneously at an EV charging station, the remainder of this report will focus on EVSE growth.

\subsection{Public Charging Trends}

As previously mentioned, public EV charging refers to EV charging stations that are available to all EV drivers and located in publicly accessible locations, such as commercial locations or along highway corridors. In Q3, the number of public EVSE in the Station Locator increased by 5,742, bringing the total number of public EVSE in the Station Locator to 88,093 and representing a $7.0 \%$ increase since Q2. The following sections break down the growth of public EVSE by charging level, network, region, and state.

\subsubsection{By Charging Level}

As shown in Fig. 5, the majority of public EVSE in the Station Locator are Level 2, followed by DC fast and Level 1. In Q3, DC fast EVSE increased by the greatest percentage (8.4\%), while Level 1 EVSE decreased by 2.1\% (Fig. 5). The decrease in public Level 1 EVSE can be attributed to a decrease in Level 1 EVSE on the ChargePoint network, particularly on the West Coast (California, Oregon, and Washington) and in Texas, though the ChargePoint network grew overall in Q3.

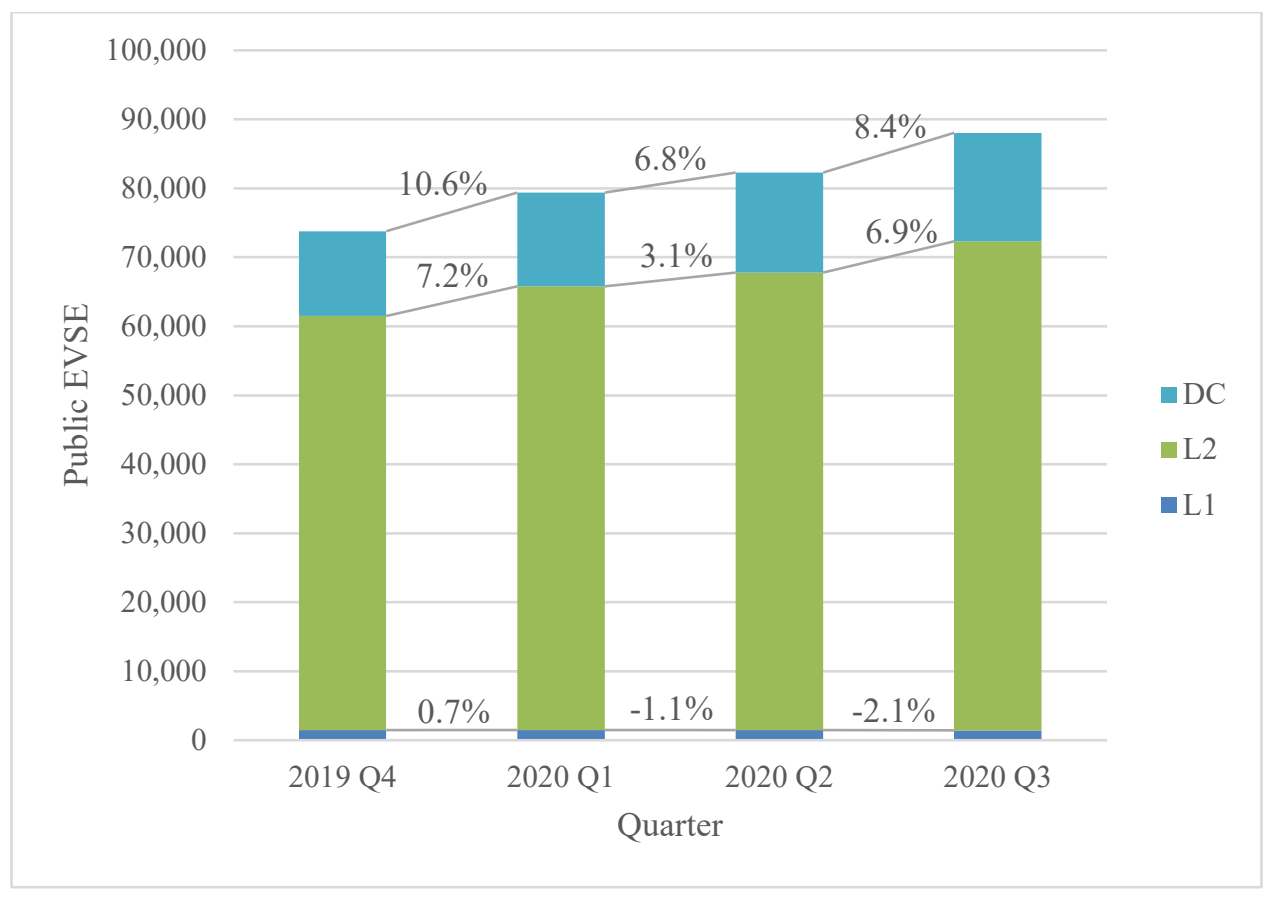

Figure 5. Quarterly Growth of Public EVSE by Charging Level.

When compared with Level 1 and Level 2 chargers, DC fast chargers have the highest power output and therefore provide the most charge in the least amount of time. DC fast chargers have a standard power output of $50 \mathrm{~kW}$, though DC fast chargers with higher levels of power output are available. Extreme fast charging infrastructure, which has a power output of $350 \mathrm{~kW}$ or more, 
was introduced in 2018. However, as shown in Fig. 6, the majority of DC fast EVSE in the Station Locator still currently have the standard power output of $50 \mathrm{~kW}$ or less.

It is important to point out that of the 15,727 public DC fast EVSE in the Station Locator, power output data is currently only available for $36.5 \%$; Fig. 6 is therefore based on power output data for 5,733 DC fast EVSE. NREL is in the process of integrating updated OCPI-based APIs to streamline the collection of power output data and create a more complete set of data. Additionally, if a DC fast EVSE has two connectors with different power outputs, only the maximum power output is counted in Fig. 6.

As shown in Fig. 6, the number of EVSE with a power output less than $51 \mathrm{~kW}$ grew by the largest percentage in Q3 (11.1\%). The number of EVSE with a power output between $51 \mathrm{~kW}$ and $299 \mathrm{~kW}$ and $300 \mathrm{~kW}$ and greater decreased by $1.2 \%$ and 9.7\%, respectively (Fig. 6). The decrease in the number of EVSE with a power output between $51 \mathrm{~kW}$ and $299 \mathrm{~kW}$ can be attributed to the EVgo network, while the decrease in the number of EVSE with a power output of $300 \mathrm{~kW}$ and greater can be attributed to the Electrify America network. Both networks temporarily adjust the power output of their DC fast chargers to $50 \mathrm{~kW}$ while maintenance or upgrades are being performed, resulting in an increase in the DC fast EVSE with a power output of $50 \mathrm{~kW}$, and a decrease in the DC fast EVSE with a power output of $51 \mathrm{~kW}$ and greater. Due to this, the Station Locator team expects to continue to see fluctuations in DC fast EVSE power output data.

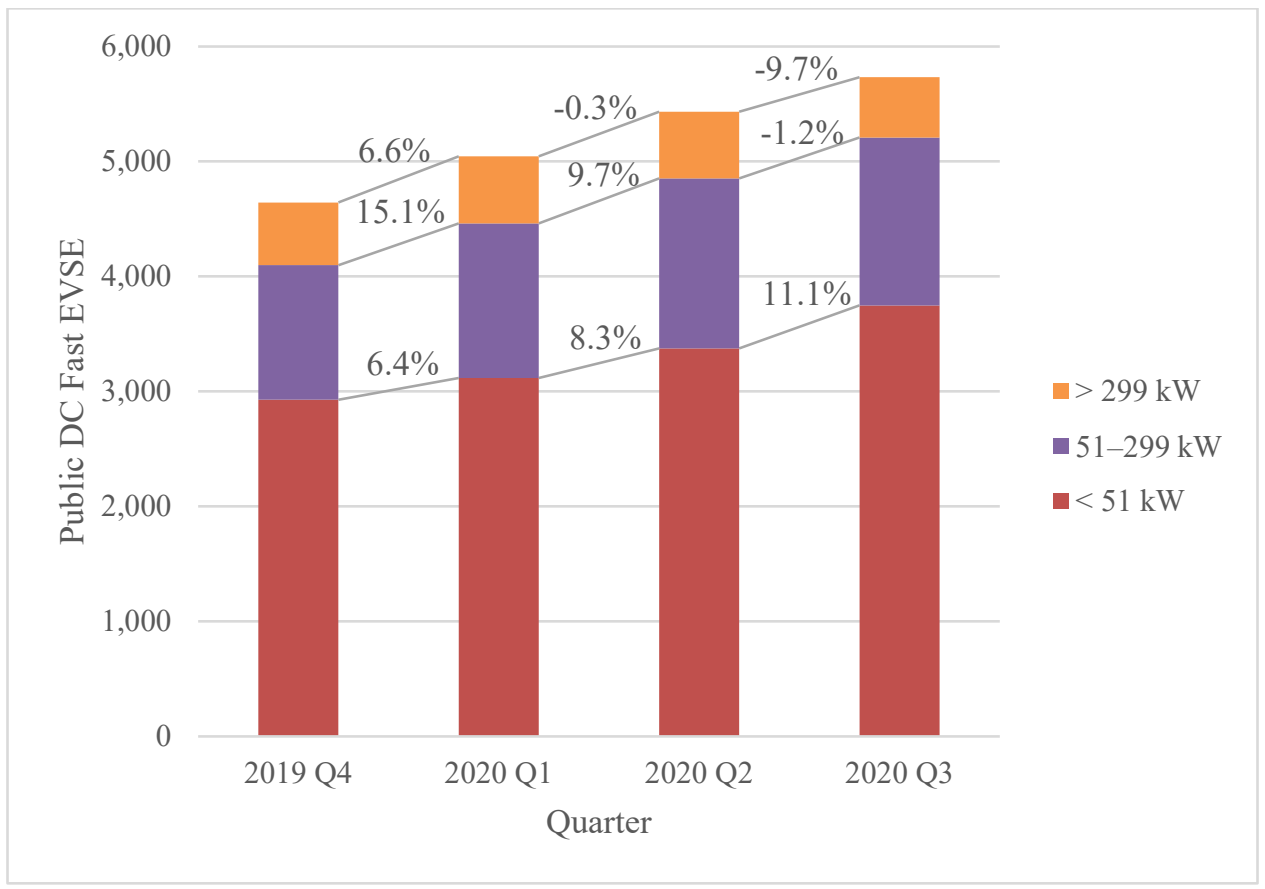

Figure 6. Quarterly Growth of Public DC Fast EVSE by Power Output.

There are currently three types of connectors that are available for DC fast chargers: CHAdeMO, CCS, and Tesla. Of the 17,918 DC fast connectors in the Station Locator as of Q3, Tesla connectors made up the largest proportion of connectors, as well as grew by the largest 
proportion (8.8\%) (Fig. 7). This growth is largely due to the Tesla Supercharger update that the Station Locator received in Q3, as discussed in section 1.1.2.

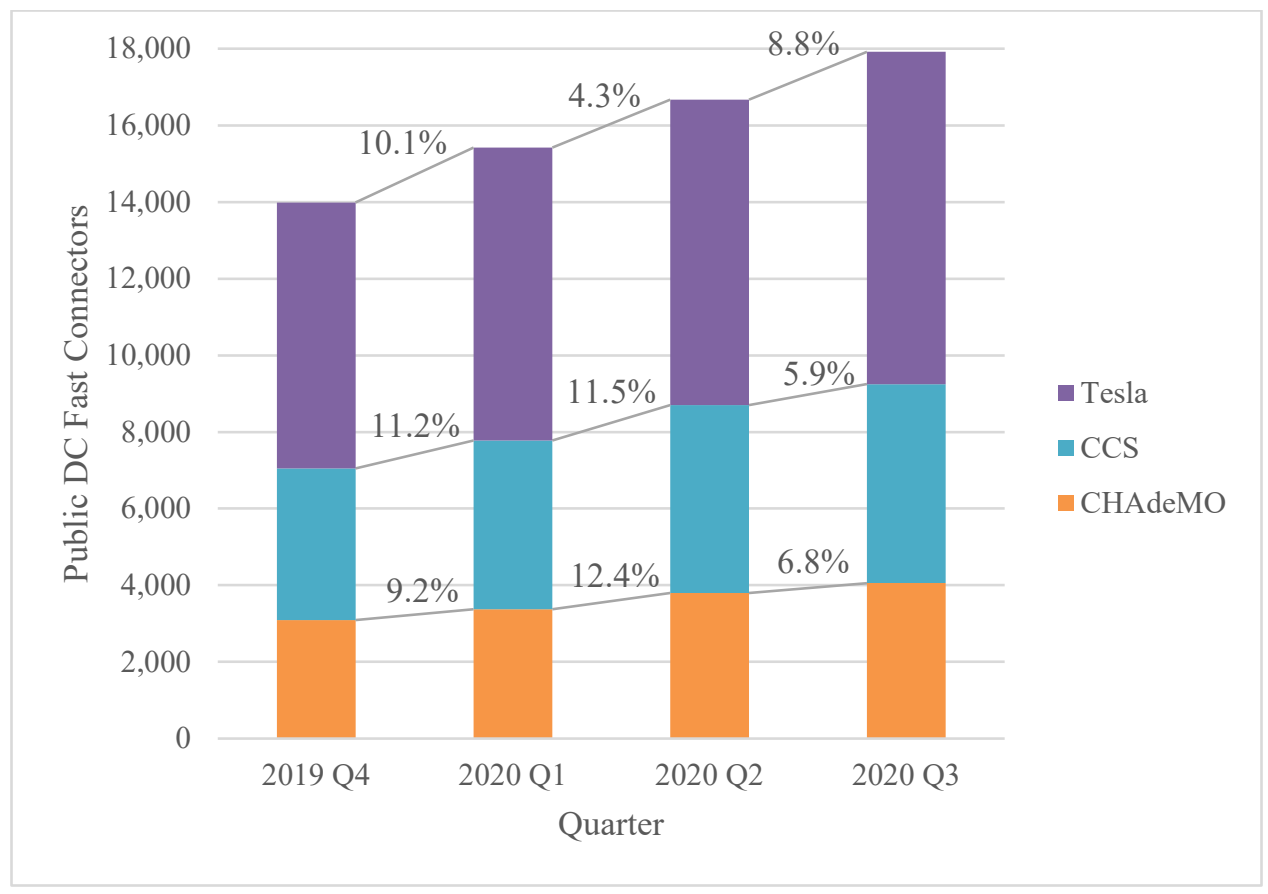

Figure 7. Quarterly Growth of Public DC Fast Connectors by Type.

\subsubsection{By Network}

As discussed in section 1.1, the Station Locator team works with most major EVSPs to collect EV charging infrastructure data for the Station Locator. Currently, the Station Locator includes stations on the below networks. The evGatway, FPL EVolution, and Powerflex networks are new to the Station Locator as of Q3. In addition, the Station Locator contains non-networked (NON) station data, which includes stations that were previously networked.

- $\operatorname{Blink}(\mathrm{BN})$

- ChargePoint (CPN)

- Electrify America (EA)

- EV Connect (EVC)

- evGateway (EVGATEWAY)

- EVgo (EVN)

- Francis Energy (FCN)

- FLO (FLO)

- FPL EVolution (FPLEV)
- Greenlots (GRN)

- OpConnect (OC)

- Powerflex (POWERFLEX)

- SemaConnect (SCN)

- Tesla Supercharger (TESLA)

- Tesla Destination (TESLAD)

- Volta (VLTA)

- Webasto (WEB)

As of the end of Q3, the ChargePoint network accounted for the largest number of public EVSE (42.6\%) in the Station Locator, and Level 2 chargers comprised the majority of ChargePoint's network (Fig. 8). This holds true for many of the networks in the Station Locator, except for the 
Electrify America, EVgo, Francis, FPL EVolution, and Tesla Supercharger networks, which are predominately, if not completely, made up of DC fast chargers.

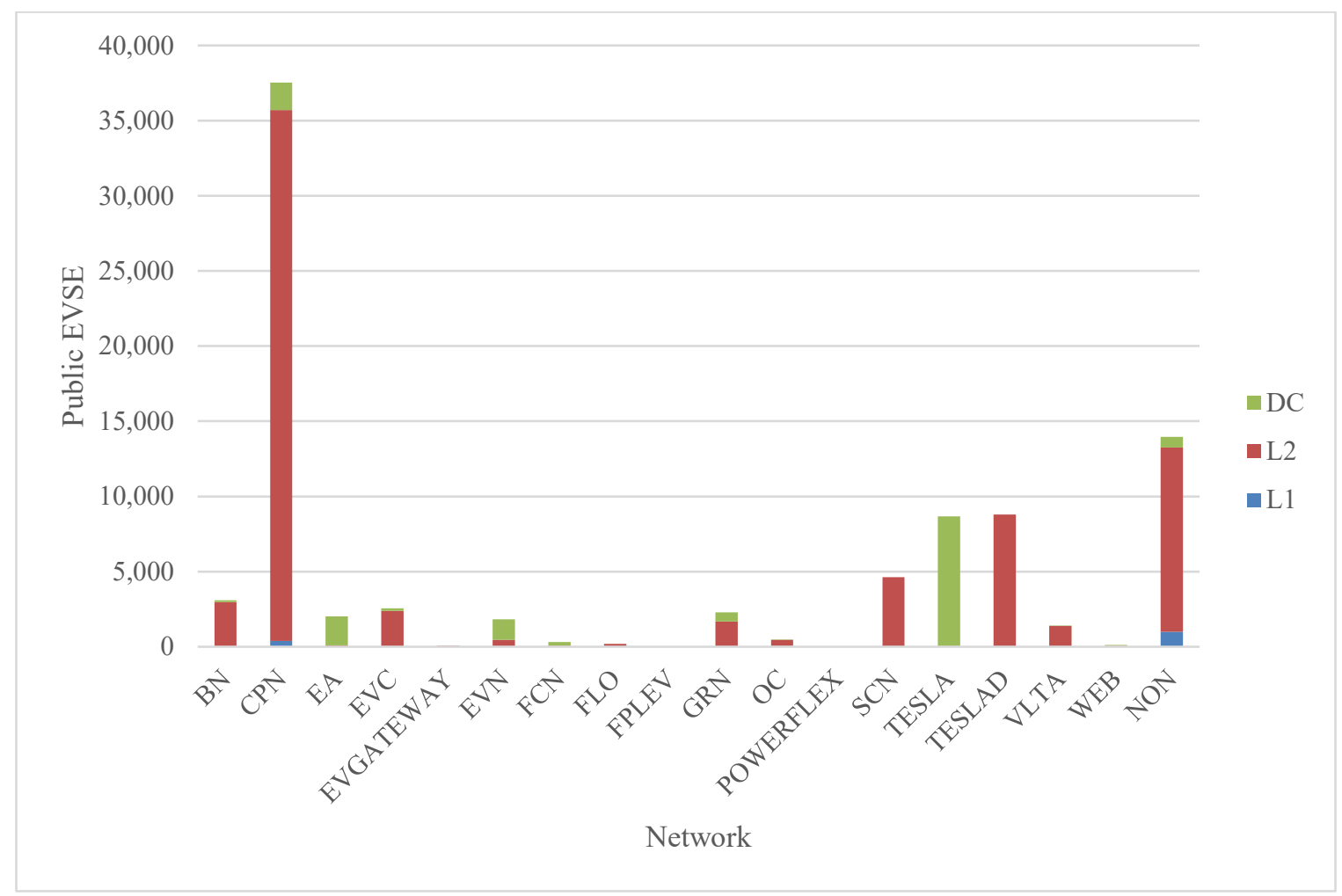

Figure 8. Breakdown of Public EVSE by Network and Charging Level in Q3.

Fig. 9 shows the growth of each network in Q3, and Table 1 includes the percent growth of each network in Q3. The number of public EVSE on all networks grew in Q3 except for the Francis network and the Webasto network, which did not grow (Table 1). The Francis network did not grow in Q3 as the Station Locator team did not receive an update for this network, as discussed in section 1.1.2. However, the Station Locator team received a large update from the Francis network in Q2, as reflected in Table 1, and expects any stations added in Q3 to be reflected in future quarters. EVSE on the Webasto network are automatically uploaded to the Station Locator via an API, but the number of Webasto EVSE in the Station Locator has remained fairly constant for over a year.

The number of EVSE on the OpConnect network increased by the largest percentage in Q3, from 258 EVSE to 483 EVSE, due to the integration of OpConnect's API into the Station Locator, as discussed in section 1.1.1. There were also large increases on the EV Connect $(29.8 \%)$ and Tesla Supercharger (8.8\%) networks in Q3 due to updates that the Station Locator team received from these networks in Q3, as well as on the Volta network (17.9\%) due to updates provided by Chargeway. Finally, the Blink network grew by $27.3 \%$ in Q3. As discussed in the second quarterly report in this series, Blink has been replacing its first-generation chargers and expanding its network; the large increase in Q3 is likely attributed to these efforts (Brown 2020b). 


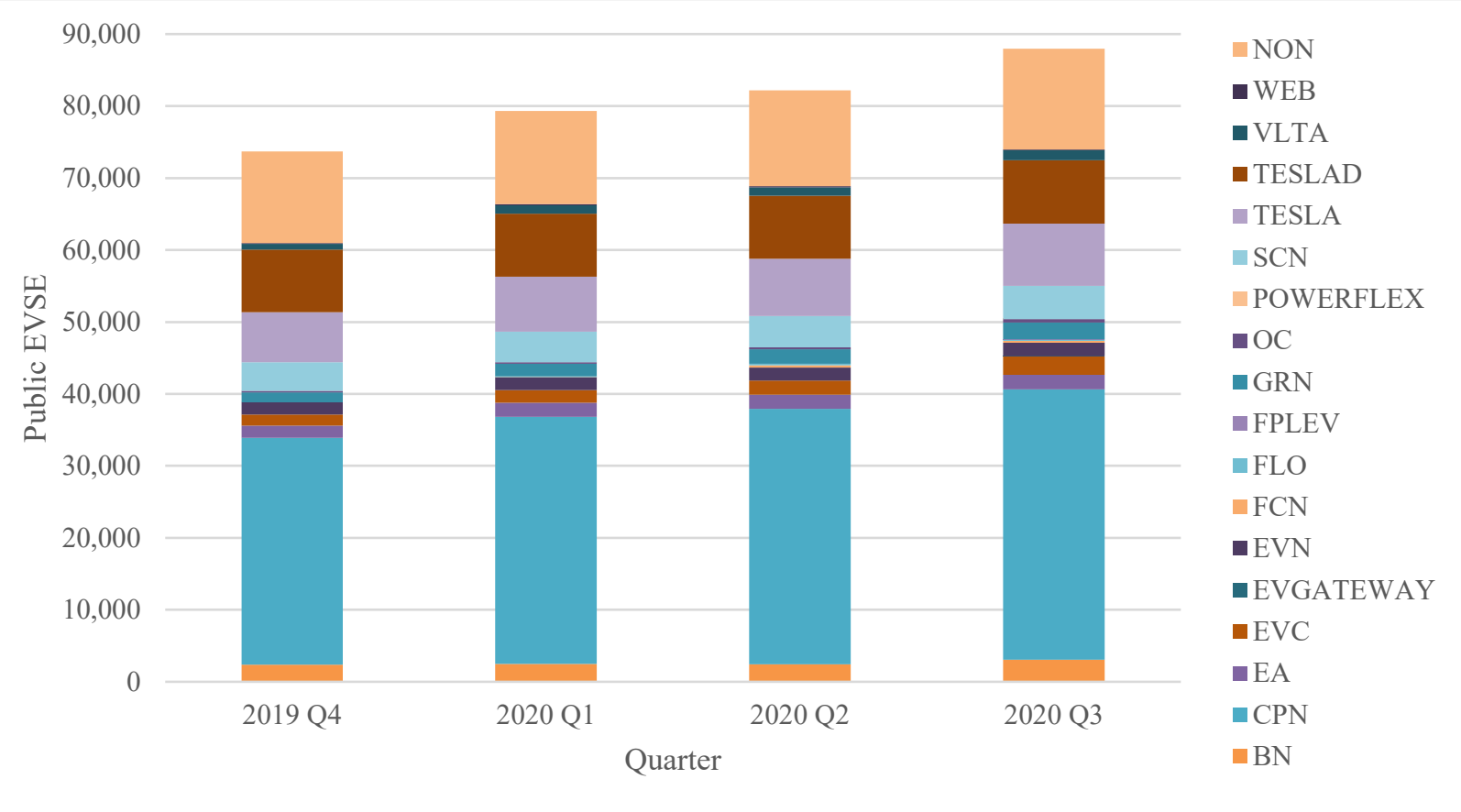

Figure 9. Quarterly Growth of Public EVSE by Network.

Table 1. Quarterly Growth of Public EVSE by Network.

\begin{tabular}{|c|c|c|c|}
\hline Network & Q1 Growth & Q2 Growth & Q3 Growth \\
\hline NON & $1.8 \%$ & $3.0 \%$ & $5.0 \%$ \\
\hline WEB & $0.9 \%$ & $-0.9 \%$ & $0.0 \%$ \\
\hline VLTA & $53.5 \%$ & $0.0 \%$ & $17.9 \%$ \\
\hline TESLAD & $0.2 \%$ & $0.0 \%$ & $0.2 \%$ \\
\hline TESLA & $10.1 \%$ & $4.3 \%$ & $8.8 \%$ \\
\hline SCN & $7.6 \%$ & $2.6 \%$ & $6.6 \%$ \\
\hline POWERFLEX & $\mathrm{N} / \mathrm{A}$ & $\mathrm{N} / \mathrm{A}$ & $\mathrm{N} / \mathrm{A}$ \\
\hline OC & $0.0 \%$ & $4.9 \%$ & $87.2 \%$ \\
\hline GRN & $24.2 \%$ & $18.9 \%$ & $13.0 \%$ \\
\hline FPLEV & $\mathrm{N} / \mathrm{A}$ & $\mathrm{N} / \mathrm{A}$ & $\mathrm{N} / \mathrm{A}$ \\
\hline FLO & $\mathrm{N} / \mathrm{A}$ & $25.8 \%$ & $3.7 \%$ \\
\hline FCN & $0.0 \%$ & $31,100.0 \%$ & $0.0 \%$ \\
\hline EVN & $3.2 \%$ & $2.2 \%$ & $1.2 \%$ \\
\hline EVGATEWAY & $\mathrm{N} / \mathrm{A}$ & $\mathrm{N} / \mathrm{A}$ & $\mathrm{N} / \mathrm{A}$ \\
\hline EVC & $17.7 \%$ & $11.2 \%$ & $29.8 \%$ \\
\hline EA & $11.9 \%$ & $2.3 \%$ & $1.2 \%$ \\
\hline CPN & $9.0 \%$ & $3.4 \%$ & $5.7 \%$ \\
\hline BN & $5.5 \%$ & $-3.4 \%$ & $27.3 \%$ \\
\hline Total & $\mathbf{7 . 6 \%}$ & $3.3 \%$ & $\mathbf{7 . 0 \%}$ \\
\hline & & & \\
\hline
\end{tabular}

\subsubsection{By Region}

The Clean Cities Coalition Network is broken down into seven regions (Fig. 10), which were used to analyze the growth of public EV charging infrastructure across the country (Clean Cities Coalition Network, n.d.b.). See the first report in this series for more information about the Clean Cities Coalition Network. 


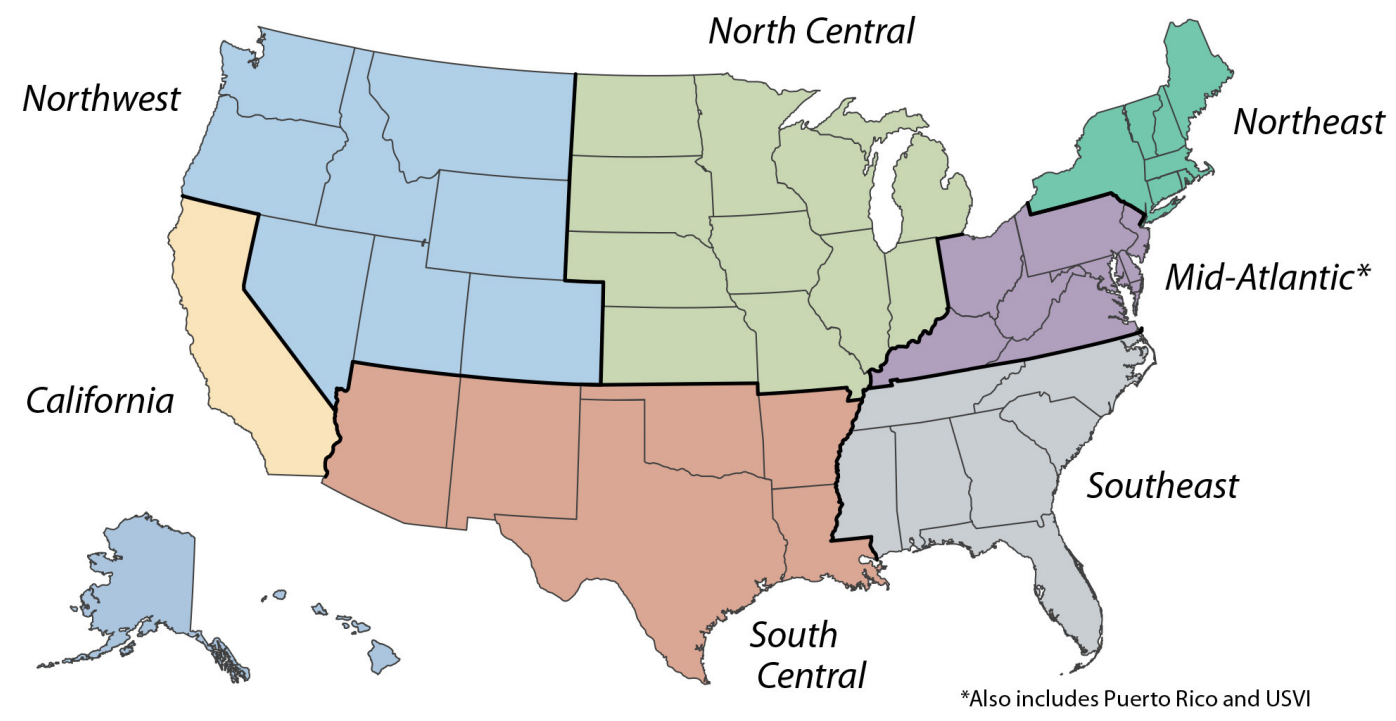

Figure 10. Clean Cities Regions.

As shown in Fig. 11, the California region had the largest share of the country's public EVSE in Q3 (31.6\%), while the South Central region had the smallest share (8.2\%). The number of public EVSE in the Mid-Atlantic region grew by the largest percentage $(9.3 \%)$, while the number of public EVSE in the North Central region grew by the smallest percentage (5.5\%) (Fig. 11).

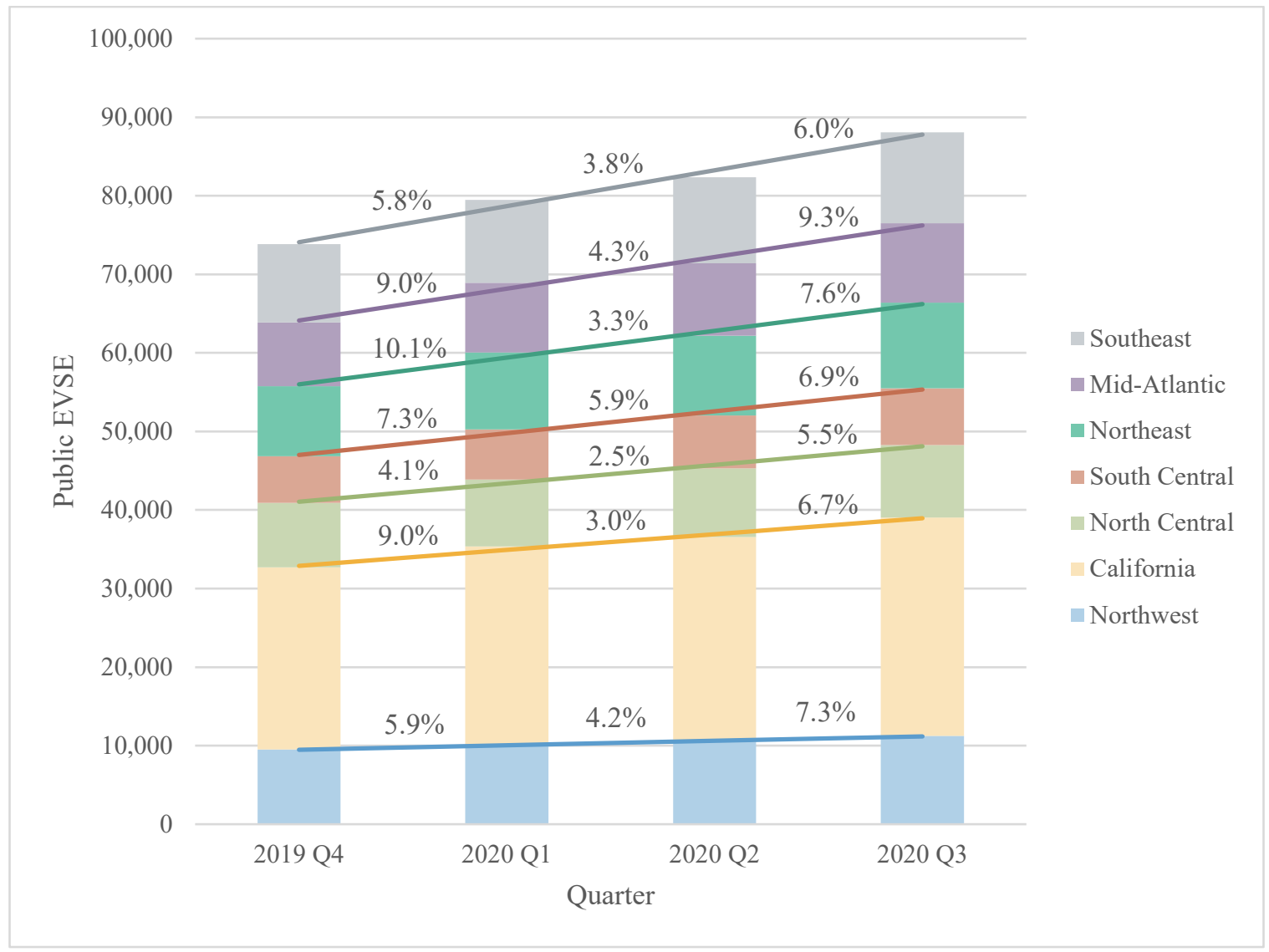

Figure 11. Quarterly Growth of Public EVSE by Clean Cities Region. 


\subsubsection{By State}

To track the growth of EVSE by state, we calculated the number of public EVSE per 100,000 people in each state. We chose this metric to compare charging infrastructure development across states on a basis that accounts for proportional impact. Washington, D.C. is considered a state for the purpose of this analysis, and the population data used is based on the U.S. Census Bureau's 2019 estimates (U.S. Census Bureau 2019).

As of the end of Q3, the number of EVSE per 100,000 people ranged from 5.6 in Alaska to 114.6 in Vermont. The five states with the highest number of EVSE per 100,000 people were Vermont, Washington, D.C., California, Hawaii, and Colorado (Table 2). However, the five states that had the largest growth of EVSE per 100,000 people were North Dakota, Montana, Alaska, Kentucky, and Washington, D.C. Note that while Alaska currently has the smallest number of EVSE per 100,000 people, Alaska was among the top five states with the largest percent growth in Q3, though this growth only reflects the addition of six ports. Similarly, North Dakota and Kentucky are among the top ten states with the smallest number of EVSE per 100,000 people, yet were among the top five states with the largest percent growth in Q3. Almost half of new EVSE in North Dakota were DC fast EVSE on the ChargePoint network, while the majority of new EVSE in Kentucky were non-networked.

Table 2. States with the Highest Rate of EVSE per 100,000 People.

\begin{tabular}{|c|c|}
\hline State & EVSE per 100,000 People \\
\hline Vermont & 114.6 \\
\hline Washington, D.C. & 74.4 \\
\hline California & 70.4 \\
\hline Hawaii & 47.2 \\
\hline Colorado & 46.0 \\
\hline
\end{tabular}

Table 3. States with the Largest Growth of EVSE per 100,000 People.

\begin{tabular}{|c|c|}
\hline State & $\begin{array}{c}\text { Q3 Growth of EVSE per } \\
\mathbf{1 0 0 , 0 0 0} \text { People }\end{array}$ \\
\hline North Dakota & $32.3 \%$ \\
\hline Montana & $25.2 \%$ \\
\hline Alaska & $17.1 \%$ \\
\hline Kentucky & $16.5 \%$ \\
\hline Washington, D.C. & $14.4 \%$ \\
\hline
\end{tabular}

\section{Private Charging Trends}

Private EV charging refers to EV charging stations that are available only to certain drivers for specific purposes, such as charging for transit fleets or employee-only charging at places of work. While the Station Locator team proactively seeks out new station openings to include in the Station Locator, the opening of private workplace chargers may not necessarily be shared publicly. The Station Locator team therefore relies on Clean Cities coalitions, industry partners, and Station Locator users to share this information. Due to the challenge in collecting this data, the number of private, non-residential charging stations in the Station Locator is likely underrepresented. 
In Q3, the number of private EVSE in the Station Locator increased by 619, bringing the total number of private EVSE in the Station Locator to 14,893 and representing a 4.3\% growth since Q2. The following sections break down the growth of private EVSE by level, as well as by two specific types: workplace charging and MUD charging.

\subsection{By Charging Level}

As shown in Fig. 12, the majority of private EVSE in the Station Locator are Level 2. However, DC fast EVSE grew by the largest percentage overall (28.3\%) in Q3 (Fig. 12). The private DC fast EVSE in the Station Locator are predominately for government fleets, including a few public transit authorities, or workplace charging.

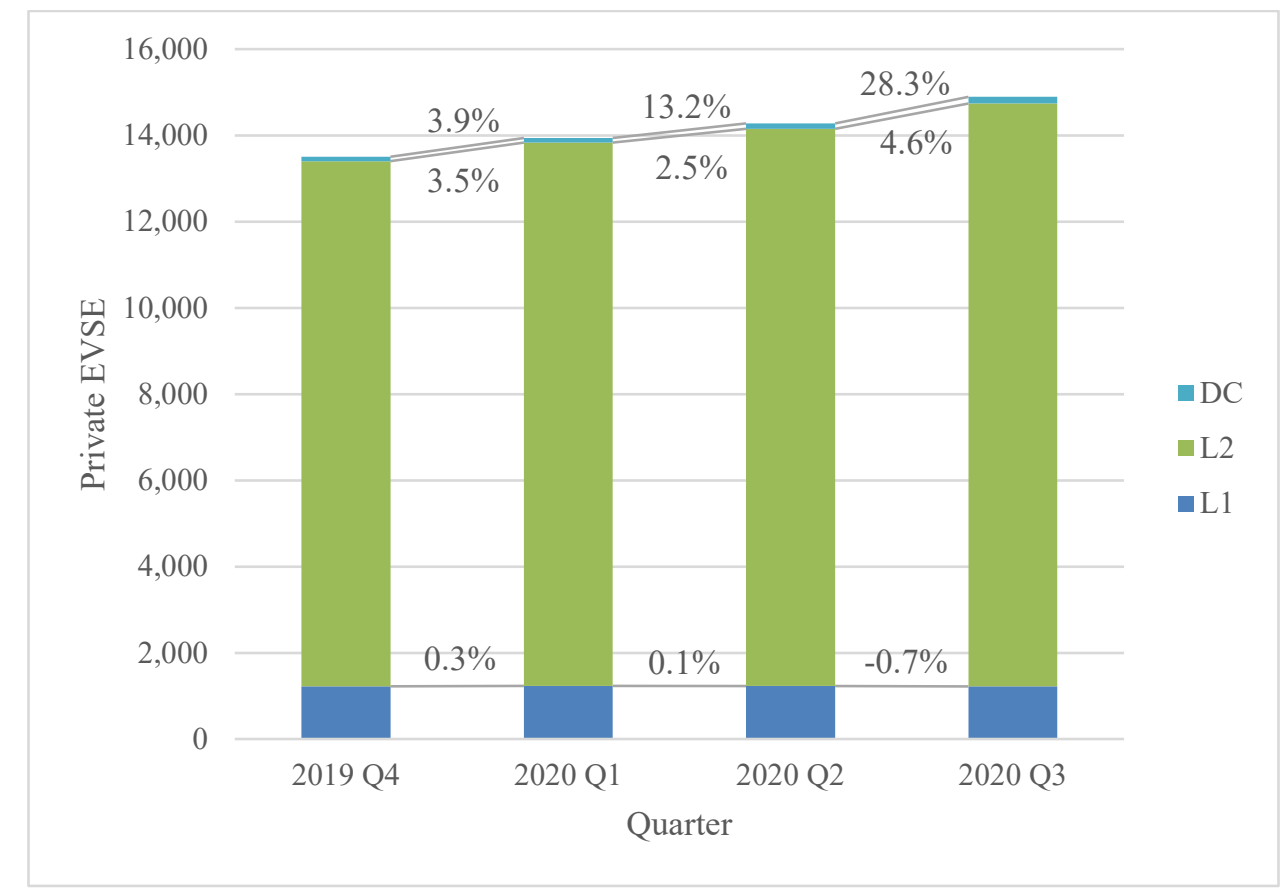

Figure 12. Quarterly Growth of Private EVSE by Charging Level.

\subsection{Workplace Charging}

Workplace EV charging infrastructure includes charging stations that are private or otherwise designated for employee use. The majority of private workplace EVSE in the Station Locator are Level 2 (Fig. 13). This is to be expected, since workplace chargers are used by employees while they are parked at work for an extended period and therefore do not necessarily need rapid charging.

As of the end of Q3, there were 8,872 workplace EVSE in the Station Locator. As shown in Fig. 13, the number of Level 2 EVSE grew by the greatest amount (7.8\%) at workplaces in Q3. 


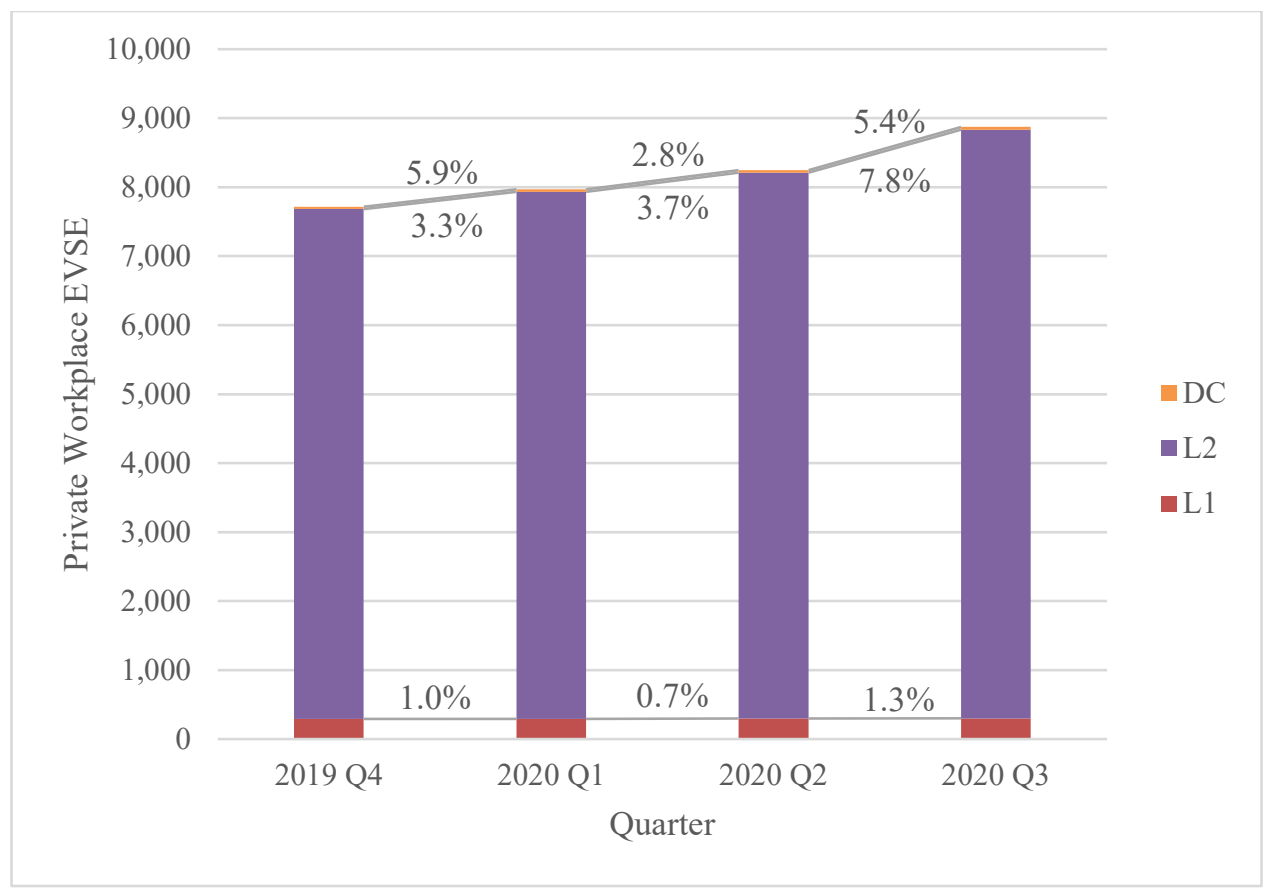

Figure 13. Quarterly Growth of Private Workplace EVSE by Charging Level.

\subsection{Multi-unit Dwelling Charging}

In 2019, the Station Locator team began a focused effort to capture private charging infrastructure installed at MUDs that is available for resident use only. In Q3, there was a 1.1\% increase in MUD EVSE, bringing the total number of private MUD EVSE to 458 (Fig. 14). MUD EVSE in the Station Locator are either Level 1 or Level 2, but only Level 2 EVSE grew in Q3 (Fig. 14).

The Station Locator team continued its concerted MUD data collection efforts in 2020 and the number of MUD EVSE is likely to continue to grow in future quarters. 


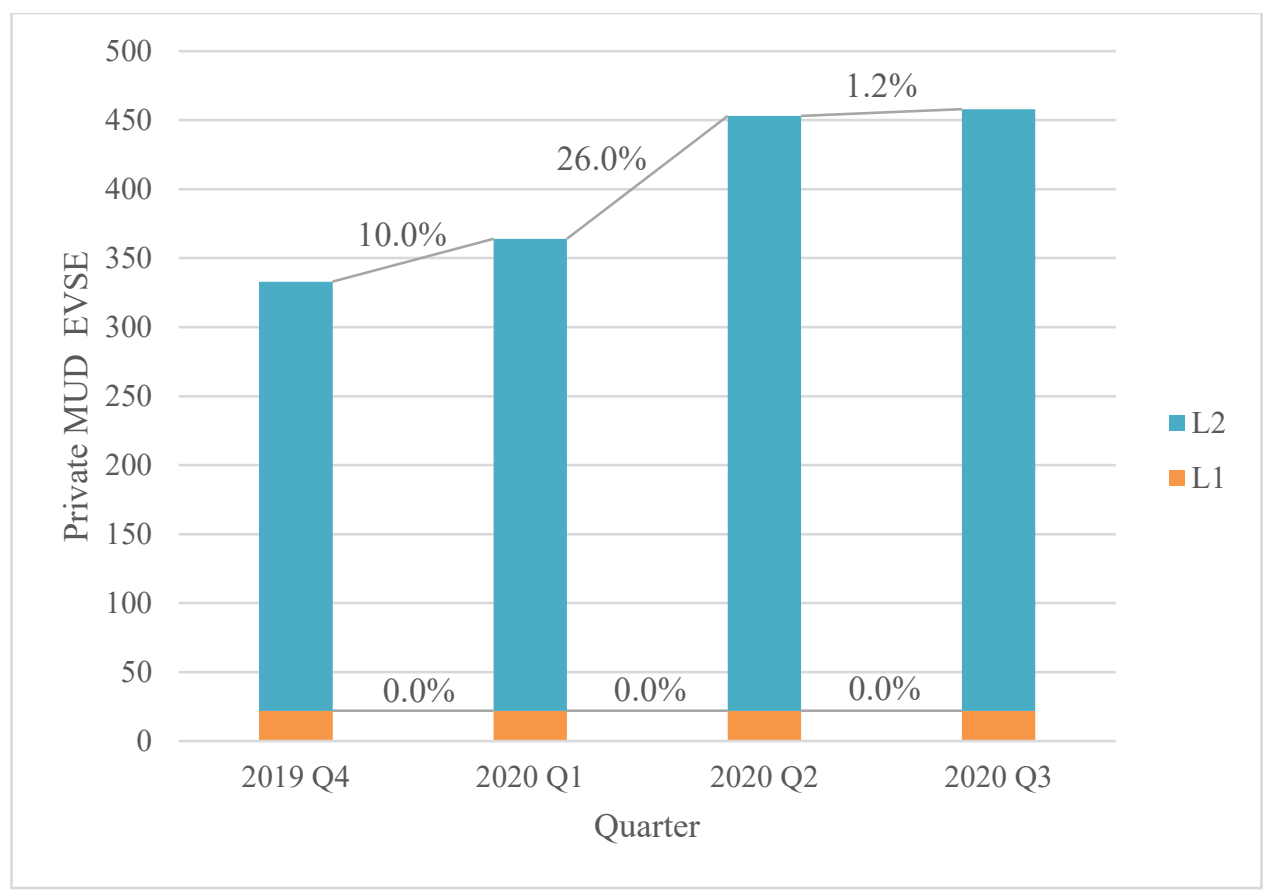

Figure 14. Quarterly Growth of Private MUD EVSE by Charging Level.

\subsection{Fleet Charging}

In 2021 the Station Locator team will focus on expanding its private fleet data collection efforts, especially for fleets that are installing charging infrastructure for medium- and heavy-duty vehicles, such as school bus fleets and public transit fleets. Once a more robust dataset is available, future quarterly reports will include data on this kind of charging infrastructure.

\section{Projecting Future Charging Infrastructure Needs}

NREL's 2017 “National Plug-In Electric Vehicle Infrastructure Analysis” estimated how much public and workplace EV charging infrastructure would be required in the United States in order to support a growing fleet of light-duty plug-in electric vehicles (PEVs), including both plug-in hybrid electric vehicles and battery electric vehicles (Wood 2017). Based on the central scenario in the analysis in which there are 15 million light-duty PEVs on the road in 2030, this analysis estimated that a total of 27,500 DC fast EVSE and 601,000 Level 2 EVSE would need to be available across the United States to meet demand for charging. This equates to $1.8 \mathrm{DC}$ fast EVSE per 1,000 PEVs and 40.1 Level 2 EVSE per 1,000 PEVs by 2030.

As of Q3, there were 15,766 public and workplace DC fast EVSE and 79,417 public and workplace Level 2 EVSE available in the United States (Fig. 15). Based on NREL's 2017 analysis, the amount of DC fast and Level 2 EVSE installed is $57.3 \%$ and $13.2 \%$, respectively, of the way toward meeting projected 2030 infrastructure requirements. As with previous quarters, it is important to note that $55.1 \%$ of public DC fast EVSE in the Station Locator are on the Tesla network and therefore only readily accessible to Tesla drivers. Additionally, as of the end of September 2020, approximately $44 \%$ of PEVs on the road were Teslas, and $62 \%$ of new PEV 
sales in Q3 were Teslas (IHS Markit, 2018; Zhou, 2020; Atlas Public Policy, 2020a). ${ }^{1}$ When public Tesla EVSE are excluded, the amount of DC fast and Level 2 EVSE currently installed is $25.8 \%$ and $11.8 \%$, respectively, of the way toward meeting projected 2030 infrastructure requirements.

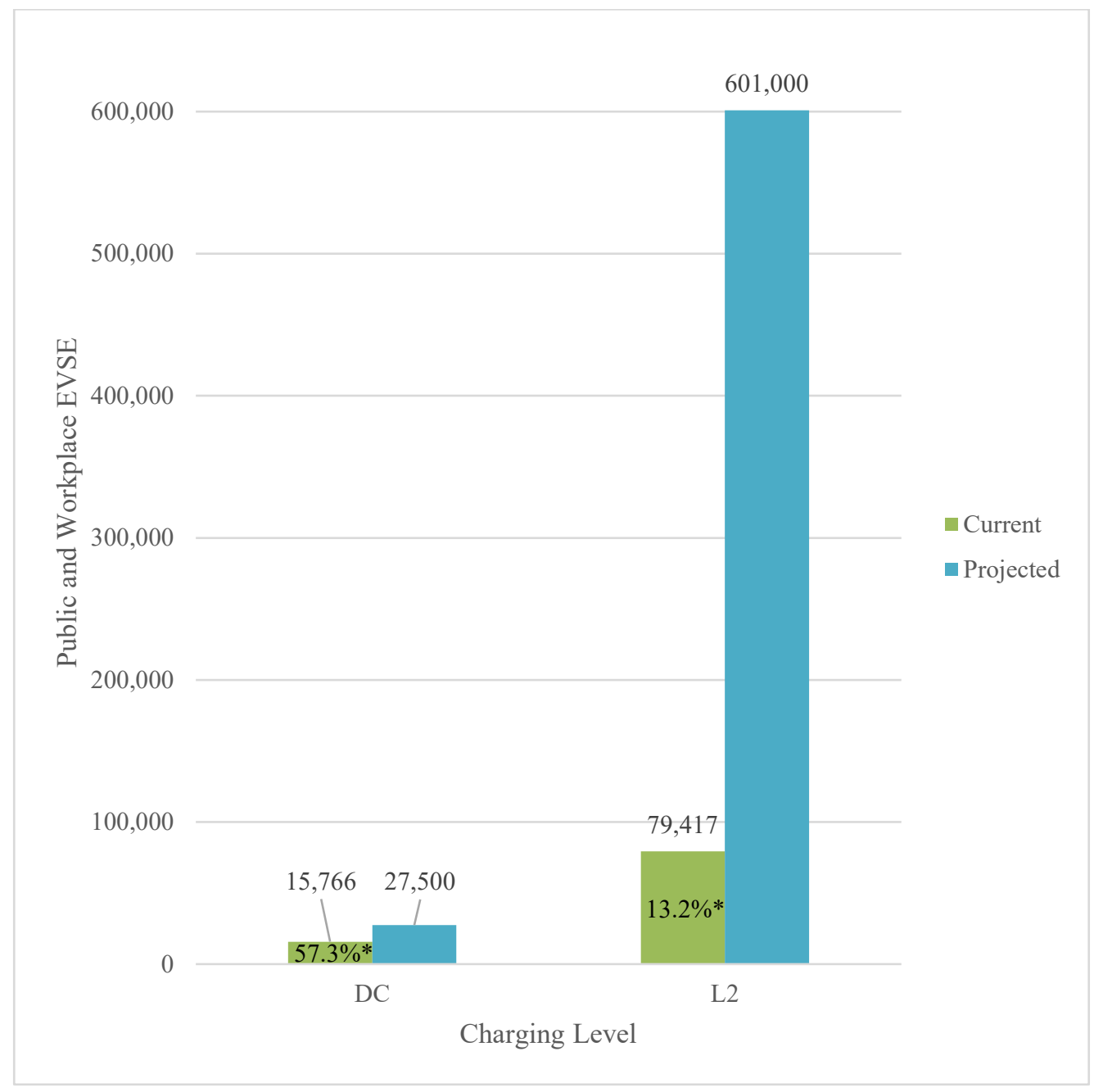

Figure 15. Current Availability and Projected 2030 Need of Public and Workplace Charging in the United States.

*Indicates the percent of projected EVSE that has been installed as of Q3.

As previously noted, NREL's 2017 analysis estimated that a ratio of 1.8 DC fast and 40.1 Level 2 EVSE per 1,000 PEVs is sufficient to meet charging demand. As of Q3, there were approximately 1.5 million PEVs in the United States' light-duty fleet (IHS Markit, 2018; Zhou,

\footnotetext{
${ }^{1}$ This percentage is based on the number of cumulative Tesla sales in the U.S. from 2011 through July 2020, 2018 PEV registration data, and 2019 and 2020 light-duty PEV sales data. This figure does not account for Teslas that have been retired since 2011 or total light-duty PEVs that were retired in 2019 and 2020.
} 
2020). ${ }^{2}$ The ratio of DC Fast and Level 2 public and workplace EVSE per 1,000 PEVs in Q3 was 10.2 and 51.5, respectively (Fig. 16). This ratio decreases to 4.6 and 45.8 when Tesla EVSE are excluded. Though this does not speak to geographic distribution of EVSE, it does indicate that, as of Q3, there was enough public and workplace DC fast and Level 2 EVSE across the United States as a whole to meet charging demand. It is notable, however, that only $10.3 \%$ of the 15 million light-duty PEVs projected for 2030 were on the road as of Q3. Light-duty PEV sales hit a record high in 2018, declined in 2019, and suffered in the first half of 2020 due to the coronavirus pandemic (Zhou, 2020). However, the U.S. PEV market bounced back in Q3, and, for the first time in 2020, experienced year-over-year growth, as discussed in the next section.

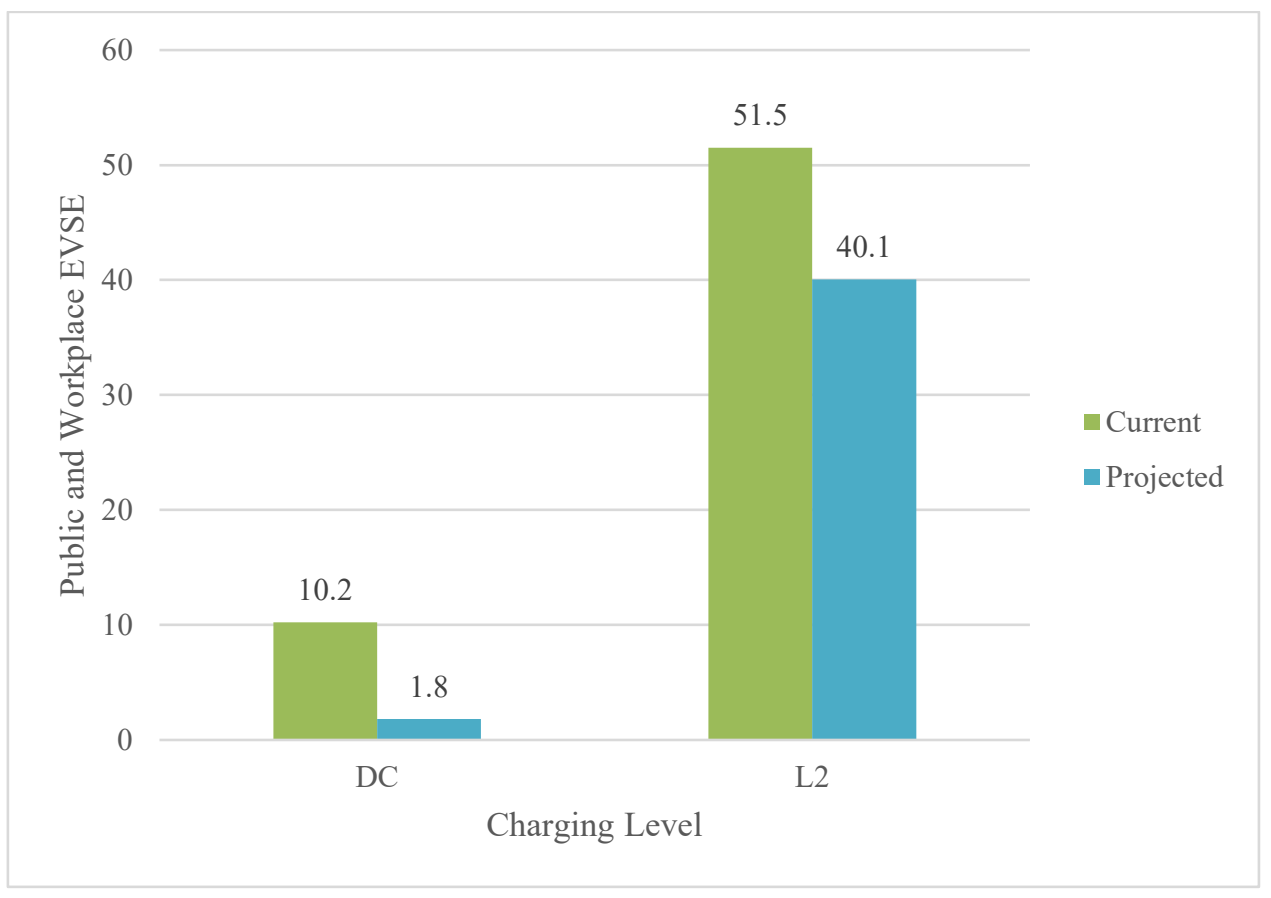

Figure 16. Current Availability and Projected 2030 Need of Public and Workplace EVSE per 1,000 EVs in the United States.

\section{Developments That Could Impact Future Quarters}

In Q3, the light-duty U.S. EV market recovered from the setbacks that occurred in the first half of 2020 due to the coronavirus pandemic. Total sales in 2020 Q3 were just two percent lower than in 2019 Q3, and September 2020 sales were 20\% higher than September 2019 sales (Atlas Public Policy, 2020a). However, when comparing 2020 year-to-date sales with 2019 year-to-date sales, U.S. EV sales have declined by 19\% (Atlas Public Policy, 2020a).

Despite the fluctuations in the U.S. EV market that have occurred throughout 2020, at the end of September, California Governor Gavin Newsom issued Executive Order N-79-20, which will effectively ban the in-state sale of new gasoline-powered light-duty vehicles by 2035 and help to

22019 and 2020 PEV registration data are not yet available. The number of PEVs as of September 2020 is based on 2018 PEV registration data and 2019 and 2020 light-duty PEV sales data. Therefore, the 1.4 million figure does not account for vehicles that were retired in 2019 and 2020, and may overestimate the number of PEVs on the road. 
permanently bolster new EV sales. The executive order requires the California Air Resources Board (ARB) to develop a plan to phase out new sales of gasoline-powered light-duty vehicles by increasing the volume of new zero-emission vehicle sales until $100 \%$ is reached in 2035 (Office of Governor Gavin Newsom 2020). The executive order also requires the California Energy Commission, ARB, and the California Public Utilities Commission to assess the state's zero-emission vehicle fueling infrastructure to support the new order. A week later, Governor Newsom signed Assembly Bill 841, which will require California utilities to pay for the grid updates and infrastructure required to support EV charging deployment on the utility side of the meter, thereby reducing costs to site hosts that can act as a significant barrier to charging infrastructure development (Atlas Public Policy, 2020b).

While California is the first and only state in the U.S. to ban the sale of new gasoline-powered vehicles thus far, other states will likely follow suit. Just a few weeks following California's announcement, the New Jersey Department of Environmental Protection released a report outlining measures that the state needs to take to meet its greenhouse gas emission reduction requirements under its Global Warming Response Act (Barr 2020). One of the recommendations included in the report is to phase out the sale of new gasoline-powered light-duty vehicles and transition to all-electric sales by 2035, as well as to build out a statewide EV charging network.

In addition to state mandates, private partnerships will continue to expand EV charging infrastructure in the U.S. At the end of July, General Motors (GM) and EVgo announced plans add 2,700 new DC fast chargers to the EVgo network, tripling its current size (General Motors 2020). The effort will be focused on improving charging access for EV drivers that live in multiunit dwellings, renters who are unable to install chargers at home, and those who may not have charging available at their workplace. As such, GM and EVgo will target public, high-traffic locations for their new chargers, such as grocery stores, retail outlets, and entertainment centers. The new stations will begin coming online in early 2021.

Similar to Lyft's pledge in June to electrify 100\% of its fleet by 2030 (Lyft, 2020), Uber announced a goal to have $100 \%$ of Uber rides in the U.S. be in EVs by 2030, and to fully electrify its fleet internationally by 2040 (Khrosrowshahi 2020). To support this effort, Uber has pledged $\$ 800$ million through 2025 to help drivers on its platform transition to EVs, and has established partnerships with GM, Renault, Nissan, and Mitsubishi to offer discounts to its drivers (Bellon 2020). Uber has also partnered with EVgo to offer discounts to its drivers that charge at EVgo stations (Uber n.d.).

Finally, the Station Locator data collection and management processes will continue to impact future EVSE counts as well. As noted in section 1.1.1, since 2019, the Station Locator team has been transitioning its counting logic to align with the hierarchy defined in the OCPI protocol: locations, EVSE, and connectors (EVRoaming Foundation, n.d.). With this transition, the Station Locator is now counting the number of EVSE at a station location rather than the number of connectors previously counted. For example, a charging location with one EVSE and two connectors was previously counted twice but is now only counted once using the OCPI protocol's counting logic. As of Q3, all manually collected data, as well as EVSE on the Electrify America and EVgo networks, are counted according to the OCPI logic. NREL is currently working with ChargePoint and Greenlots to integrate their OCPI APIs into the Station Locator, and expects both integrations to be complete in the first quarter of 2021. Additionally, 
as discussed in section 1.1.1., NREL is continuously working with EVSPs to add new APIs to the Station Locator. As these new APIs come online, there will likely be an increase in the number of EVSE in the Station Locator.

\section{Conclusion}

This paper examines the growth of EV infrastructure, including the growth of public EV charging by charging level, network, region, and state, and the growth of private EV charging by charging level and use type (i.e., workplace and MUD), in the Q3 of 2020. With such rapid growth and change in EV charging infrastructure, the information presented in this paper aims to help readers understand how and where the infrastructure is developing, where there may be areas of opportunity, and whether development is keeping pace with projected charging demand.

As of the end of Q3, Level 2 chargers accounted for the majority of both public and private EVSE in the Station Locator (80.5\% and $90.8 \%$, respectively), though public and private DC fast EVSE grew by the largest percentage ( $8.4 \%$ and $28.3 \%$, respectively). California continues to lead the country in terms of the total number of public EVSE available (27,801 EVSE), but drops in rank, to third, when compared to other states based on EVSE available per 100,000 people. The Mid-Atlantic region led the country in terms of percent growth in Q3 (9.3\%), while the number of EVSE in the North Central region grew by the smallest percentage in Q3 (5.5\%).

Based on NREL's 2017 projection of the number of public and workplace Level 2 chargers required to meet charging demand in 2030, the number of DC fast and Level 2 EVSE is 57.3\% and $13.2 \%$, respectively, of the way toward meeting projected 2030 demand (Wood, 2017). The number of DC fast EVSE and Level 2 EVSE per 1,000 PEVs was 10.2 and 51.5, respectively, compared with NREL's projected need of 1.8 and 40.1, respectively. Using the projected demand ratios as a measure of current demand, this indicates that infrastructure development is keeping up with, and even surpassing, charging demand in terms of the total amount available across the United States. It is important to note that the majority (55.1\%) of public DC fast EVSE in the Station Locator are on the Tesla network, and are therefore only readily accessible to Tesla drivers.

Finally, as the Station Locator team adds new charging networks to the Station Locator and continues its concerted effort to collect MUD and fleet charging data, we will continue to see large increases in the number of EVSE available.

If there are additional metrics that readers are interested in seeing, please email suggestions to the authors at TechnicalResponse@icf.com. 


\section{Bibliography}

Alternative Fuels Data Center. n.d.a. "About the Alternative Fuels Data Center." Accessed June 5, 2020. https://afdc.energy.gov/about.html.

Alternative Fuels Data Center. n.d.b. “Alternative Fueling Station Locator.” Accessed June 5, 2020. https://afdc.energy.gov/stations/\#/find/nearest.

Alternative Fuels Data Center. n.d.c. "Data Included in the Alternative Fueling Station Data." Accessed June 5, 2020. https://afdc.energy.gov/data_download/alt_fuel_stations_format.

Atlas Public Policy. 2020a. "U.S. EV Sales Surge in September." EV Hub Weekly Digest, November 23, 2020.

Atlas Public Policy. 2020b. "California Continues Charge with New EV Infrastructure Requirements.” EV Hub Weekly Digest, October 5, 2020.

Barr Helaine, Paul Orlando, Robert Kettig, R. Christopher Barry, Rupa Karmarkar-Deshmukh, Marwa Kamel. 2020. New Jersey's Global Warming Response Act $80 x 50$ Report. New Jersey Department of Environmental Protection. https:/www.nj.gov/dep/climatechange/docs/nj-gwra80x50-report-2020.pdf.

Bellon, Tina. 2020 "Uber promises $100 \%$ electric vehicles by 2040 , commits $\$ 800$ million to help drivers switch." Reuters, September 15, 2020. https://www.reuters.com/article/uber-electricvehicles/uber-promises-100-electric-vehicles-by-2040-commits-800-million-to-help-driversswitch-idUSKBN25Z2TX.

Brown, Abby, Stephen Lommele, Alexis Schayowitz, and Emily Klotz. 2020a. Electric Vehicle Charging Infrastructure Trends from the Alternative Fueling Station Locator: First Quarter 2020. Golden, CO: National Renewable Energy Laboratory. NREL/TP-5400-77508. www.nrel.gov/docs/fy20osti/77508.pdf.

Brown, Abby, Stephen Lommele, Alexis Schayowitz, and Emily Klotz. 2020b. Electric Vehicle Charging Infrastructure Trends from the Alternative Fueling Station Locator: Second Quarter 2020. Golden, CO: National Renewable Energy Laboratory. NREL/TP-5400-78486. https://www.nrel.gov/docs/fy21osti/78486.pdf.

Clean Cities Coalition Network. n.d.a. “About Clean Cities.” Accessed June 5, 2020. https://cleancities.energy.gov/about/.

Clean Cities Coalition Network. n.d.b. "Technology Integration Program Contacts." Accessed June 5, 2020. https://cleancities.energy.gov/contacts/?open=regional\#headingregionalManagers.

EVRoaming Foundation. 2019. OCPI 2.2: Open Charge Point Interface. Document Version 2.2, September 30, 2019. https://ocpi-protocol.org/app/uploads/2019/10/OCPI-2.2.pdf. 
General Motors. 2020. "General Motors and EVgo aim to accelerate widespread EV adoption by adding fast chargers nationwide." GM Corporate Newsroom, July 31, 2020.

https://media.gm.com/media/us/en/gm/home.detail.html/content/Pages/news/us/en/2020/jul/0731 -evgo.html

IHS Markit. 2018. Derived Vehicle Registration Data by Fuel Type for the U.S. Golden, Colorado: National Renewable Energy Laboratory.

Levene, Johanna, Stephen Lommele, Robert Eger, and Wendy Dafoe. 2019. "Developing a Comprehensive Database of Alternative Fuel Station Locations across Canada and the United States of America." In Canadian Transportation Research Forum $54^{\text {th }}$ Annual Conference Proceedings, 2019.

Lyft. 2020. "Leading the Transition to Zero Emissions: Our Commitment to $100 \%$ Electric Vehicles by 2030." Lyft Blog, June 17, 2020. https://www.lyft.com/blog/posts/leading-thetransition-to-zero-emissions?mc cid=9de7a585ad\&mc_eid=91b6b5e247

Khrosrowshahi, Dara. 2020. "Driving a Green Recovery.” Uber Newsroom, September 8, 2020. https://www.uber.com/en-AE/newsroom/driving-a-green-recovery/.

Office of Governor Gavin Newsom. 2020. "Governor Newsom Announces California Will Phase Out Gasoline-Powered Cars \& Drastically Reduce Demand for Fossil Fuel in California's Fight Against Climate Change." CA.gov, September 23, 2020.

https:/www.gov.ca.gov/2020/09/23/governor-newsom-announces-california-will-phase-outgasoline-powered-cars-drastically-reduce-demand-for-fossil-fuel-in-californias-fight-againstclimate-change/.

Uber. n.d. "Together on the road to zero emissions." Accessed December 18, 2020. https://www.uber.com/us/en/drive/services/electric/.

U.S. Census Bureau. 2019. "NST-EST2019-01: Table 1. Annual Estimates of the Resident Population for the United States, Regions, States, and Puerto Rico: April 1, 2010 to July 1, 2019." Accessed June 5, 2020. https:/www.census.gov/newsroom/press-kits/2019/national-stateestimates.html.

Wood, Eric, Clément Rames, Matteo Muratori, Sesha Raghavan, and Marc Melaina. 2017. National Plug-In Electric Vehicle Infrastructure Analysis. Golden, CO: National Renewable Energy Laboratory. https://www.nrel.gov/docs/fy17osti/69031.pdf.

Zhou, Joann. 2020. Annual U.S. Plug-In Electric Vehicle Sales, 2020. Distributed by Argonne National Laboratory. 